\title{
A GROUND LEVEL STUDY OF HEALTH PROBLEMS OF DOMESTIC WORKERS DURING COVID 19 PANDEMIC
}

\author{
Dimpal Vij*1, Anjana ${ }^{2}$ \\ 1. Department of Economics, MMH College, Ghaziabad, U.P., India \\ 2. Research Scholar, MMH College, Ghaziabad, U.P., India
}

Correspondence: dimpal.vij@rediffmail.com

\begin{abstract}
The pandemic of COVID19 laid various adverse effects and made mark on domestic workers lives. Ground report shows evidences of drastic downfall in their income due to raised unemployment, increase in health expenditure, shortage of health care facilities etc. The second wave of COVIDI9 has created havoc in their life as their work leaves no savings for them. This article based on field study argues the health complexities that have arisen in domestic workers lives during pandemic. It has subjected struggles of domestic workers for health and medication facilities during and after pandemic. It also suggests the corrective measures that government can take to bring out these workers from these drudgeries and impact of circular economic concept to sustain their lives comfortable.
\end{abstract}

\section{KEYWORDS}

Covid 19, Pandemic, Health, Domestic workers, Circular Economy (CE)

The paper was presented at the AICTE International Conference on Circular Economy, Management and Industry, Bharati Vidyapeeth's Institute of Management Studies and Research, Navi Mumbai and Apeejay School of Management, Dwarka, Delhi, India. October 2021

\section{INTRODUCTION}

The implications of covid19 have been admitted throughout the economies. Recent years (2020-2021) brought extremely unbeatable challenges to everybody at different levels. It largely devastated marginalised and accessible section of our society. As lockdown was announced due to covid, it resulted in several casualties like job loss, shortage of food and basic necessities, educational inadequacy and most important downswing in health and income bringing this crisis ahead. The second wave swept numbers of lives, employment, savings and raised health emergencies. Also, it deprived nutritional deficiency among the families of domestic workers.
Although economic burdens and health complexities are not fresh evolved issues but yes, still critical matter of concern for domestic workers. All these inabilities belong to domestic workers formed an unbalanced structure during pandemic.

Recovery at socio-economic levels is quite far but matter of concern is diagnosis and recovery of physical-mental health of vulnerable section. Pandemic reduced the structured work opportunities that increased health expenditure and economic burdens of these workers. Instead of, workers those employed faced high-risk conditions because 'no work no compensation, cleared to them. Fear of retrenchment has been noticed among the 
workers and health issues were almost common at both phases and mental health issues were not concerned at all and did not seek special treatment. Of course, other health issues (injuries, fever, cough, headache, etc.) considered as minor problem and treated as common by these workers and they took medicines causally from medical stores. Government's concern towards this vulnerable section made much benefits which fulfilled their starvation during lockdown I and II as well. Even though several steps have been taken by government for example free rationing, vaccination and sanitization despite there is a large number of this population stayed untouched to be benefitted.

\section{LITERATURE REVIEW}

[1] have mentioned in their research paper female domestic workers poses hectic schedule as they have to maintain work-life balance. More often they have to work more than one house along with their family responsibilities. But they lack behind caring themselves which led several mental and health complexities.

[2] research paper assessed the living conditions and physical health profile of these female domestic workers. It has been concerned lack of care and attentive measures towards physical and mental health created detritions in their life.

[3] in their research paper mentioned perils of lockdown. As casual employments and livelihood opportunities has been lost due to pandemic. They stated about unfavorable terms of COVID which endured by informal workers as loss of employment, starvation, health problems and other diseases too. Food and nutritional deficiency also increased at large extent at this time and forced bulk of diseases. The institute for policy studies and National domestic workers alliance [4] collectively presented a report on black immigrant domestic workers classified into personal economic impact and health \& safety vulnerability. It disclosed in the report 70 percent domestic workers either fired from their jobs or got reduced wages, faced housing insecurity and having no safety net. Lack of personal protective equipment (PPE) and no medical insurance dragged these workers at a higher exposure to COVID.
[5] submitted their report to ILO stated about occupational safety and health practices at workplace in pandemic. They laid emphasis on promoting OSH measures for the safety and without risk to health of workers. The framework suggested return to work policies with risk assessment and control strategies. These practices considered to eliminate the exposure of infection at or outside workplace and classified into practices among employers (reduce work and contact), among workers (distancing, work with caution) and governments (safety kits and other helps).

[6] this research paper highlighted the pandemic and women's work. It has been stated covid-19 seemed an additional constraint for female workers. As these workers run or support their families but due to lockdown no work, no money and no savings made situation critical.

\section{OBJECTIVES OF THE STUDY}

1. To figure out the health complexities endured by domestic workers before and during lockdowns.

2. Discussion on government intervention and further corrective measures that could help in surviving long time after pandemic crisis.

3. To conclude the future prospective of domestic workers by application of circular economic tools.

\section{RESEARCH METHODOLOGY}

This research article is a blend of both primary and secondary data. Secondary data is used to get information about domestic workers, their problems and circular economy concepts etc. For this various research articles of different journals, newspaper reports, magazines, government websites and reports by ILO, NDWA were consulted. Primary data was collected by researcher themselves to check true state of the ground reality reports as found in various secondary data. The data was collected from urban areas of Ghaziabad (Uttar Pradesh) and convenient sampling method was used. Due to time, money and manpower constraint sample size was restricted to 50 only. Data was analyzed through different statistical tools and results were interpreted.

\section{DISCUSSION AND FINDINGS}

This survey was done by researchers themselves in the month of August-September (2021) from urban areas of Ghaziabad (Uttar Pradesh) 


\begin{tabular}{|c|c|c|}
\hline Characteristics & & $(\mathrm{N}=50) \%$ \\
\hline \multirow{3}{*}{ Gender } & \multirow{3}{*}{$\begin{array}{l}\text { Female } \\
\text { Male } \\
\text { Total }\end{array}$} & $80 \%$ \\
\hline & & $20 \%$ \\
\hline & & 100 \\
\hline \multirow{5}{*}{ Age (yrs) } & \multirow{5}{*}{$\begin{array}{l}\text { 18-35 (Female) } \\
\text { above } 35 \text { (Female) } \\
\text { 18-35 (Male) } \\
\text { above } 35 \text { (Male) } \\
\text { Total }\end{array}$} & $34 \%$ \\
\hline & & $46 \%$ \\
\hline & & $14 \%$ \\
\hline & & $6 \%$ \\
\hline & & 100 \\
\hline \multirow{4}{*}{ Marital status } & \multirow{4}{*}{$\begin{array}{l}\text { Married } \\
\text { Unmarried } \\
\text { Other } \\
\text { Total }\end{array}$} & $56 \%$ \\
\hline & & $28 \%$ \\
\hline & & $16 \%$ \\
\hline & & 100 \\
\hline \multirow{5}{*}{ Education level } & \multirow{5}{*}{$\begin{array}{l}\text { Illiterate } \\
\text { Primary } \\
\text { Secondary } \\
\text { Highschool } \\
\text { Total }\end{array}$} & $18 \%$ \\
\hline & & $42 \%$ \\
\hline & & $24 \%$ \\
\hline & & $16 \%$ \\
\hline & & 100 \\
\hline \multirow{3}{*}{ Migration Status } & \multirow{3}{*}{$\begin{array}{l}\text { Migrants } \\
\text { Non-Migrants } \\
\text { Total }\end{array}$} & $28 \%$ \\
\hline & & $72 \%$ \\
\hline & & 100 \\
\hline
\end{tabular}

Source - Researchers collected data through survey (Authors' own)

As result shows that out of the total numbers of domestic workers that were surveyed $80 \%$ were female domestic workers while $20 \%$ workers were male. Among female domestic workers $34 \%$ were at the age group of 18 to 35 years while $14 \%$ male were of same age group but the data reversed above the age of 35 , only $6 \%$ domestic workers were male while $46 \%$ of female were working as domestic workers. It was found in the study that as the age grows male workers choose other profession than female workers. While females are more inclined to domestic work as this work suits to their skills and also helpful in their family work life balance. Marital status of domestic workers shows that $56 \%$ domestic workers were married, $28 \%$ were unmarried $16 \%$ other (widow, divorced etc.). As far as their education level is concerned $18 \%$ domestic workers were illiterate, $42 \%$ were educated at primary level, $24 \%$ at secondary level and $16 \%$ completed their high school. As migration was the major issue of lockdown when majority of workers moved to their original places but it was found in the study that only $28 \%$ domestic workers of these areas were migrants while $72 \%$ workers were non migrants or local residents. So far as
$44 \%$ of these domestic workers are living in nuclear family while $66 \%$ live in joint family.

Regarding job status of domestic workers during lockdown I survey found that only $28 \%$ were employed, $56 \%$ lost their jobs and $16 \%$ chose alternative tasks to raised earning as selling masks, sanitizers and worked on shops as part-time. (Figure-1)

\section{FIGURE 1}

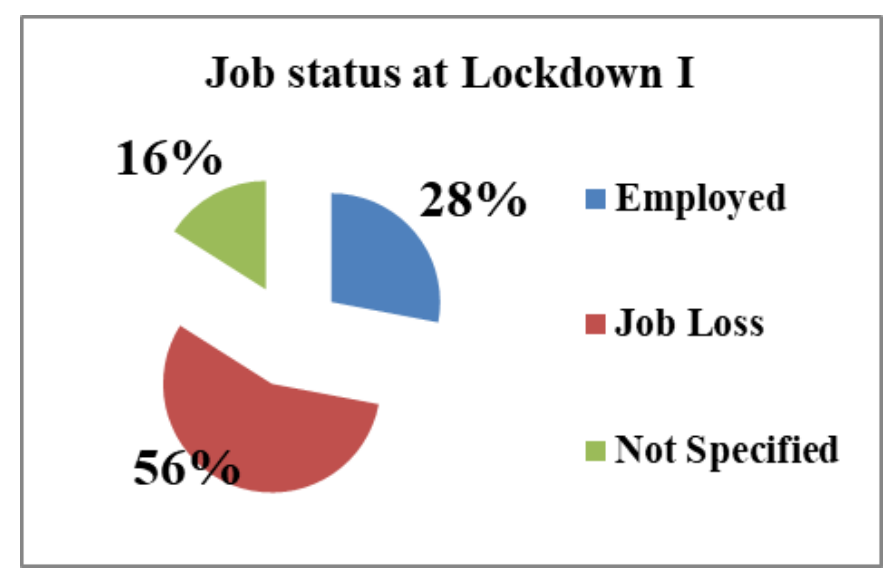




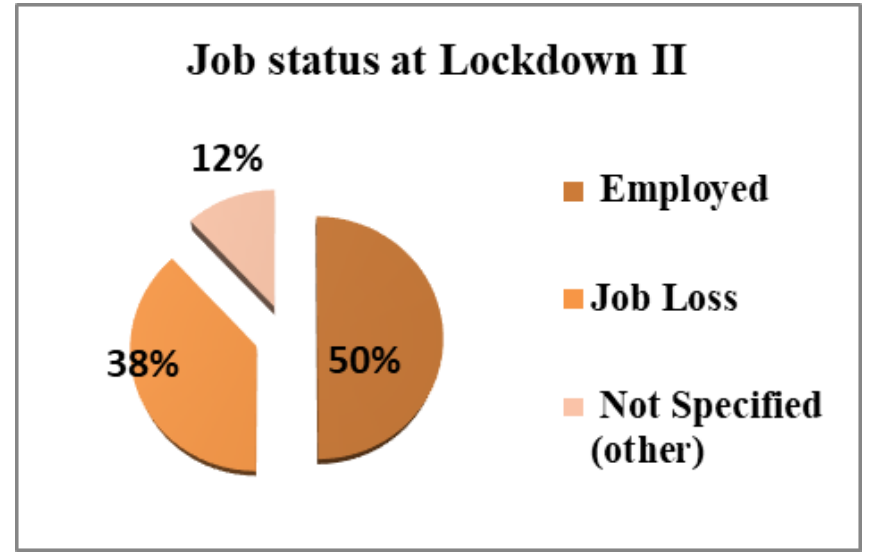

Source- Survey done by Researchers (Authors' own)

When this status was compared to Lockdown II survey found that as against lockdown I of $28 \%$ (Figure 1) in lockdown II 50\% workers were employed, 38\% lost their jobs as against $56 \%$ of lockdown I and only $12 \%$ were involved in other activities to earn from different sources (part-time jobs, selling vegetables and other things etc.) (Figure-2) Regarding health complexities at lockdown I 40\% faced certain health issues themselves (Figure-3) and 20\% told that their family members having some health problems but not diagnosed, $30 \%$ did not required any medication for their health problems $10 \%$ faced maternity problems $14 \%$ miscarriage and $6 \%$ faced complications at child birth).Whereas, health emergencies during second phase of lockdown $30 \%$ faced health issues as comparative to $40 \%$ in lockdown I while $16 \%$ of their family members faced some health problems but not diagnosed, $50 \%$ did not required any medication (minor health issues) and $4 \%$ faced maternity problems $2 \%$ miscarriage and $2 \%$ childbirth complications).

FIGURE 3

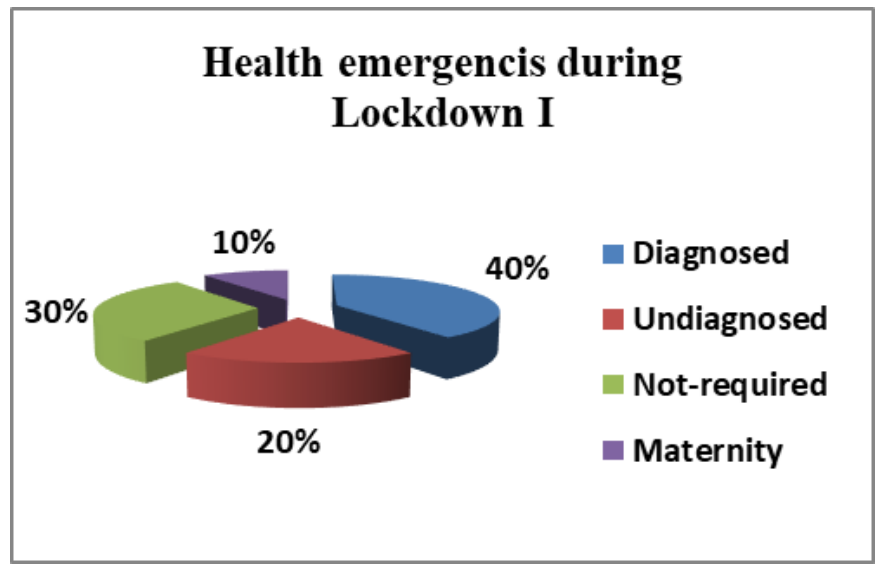

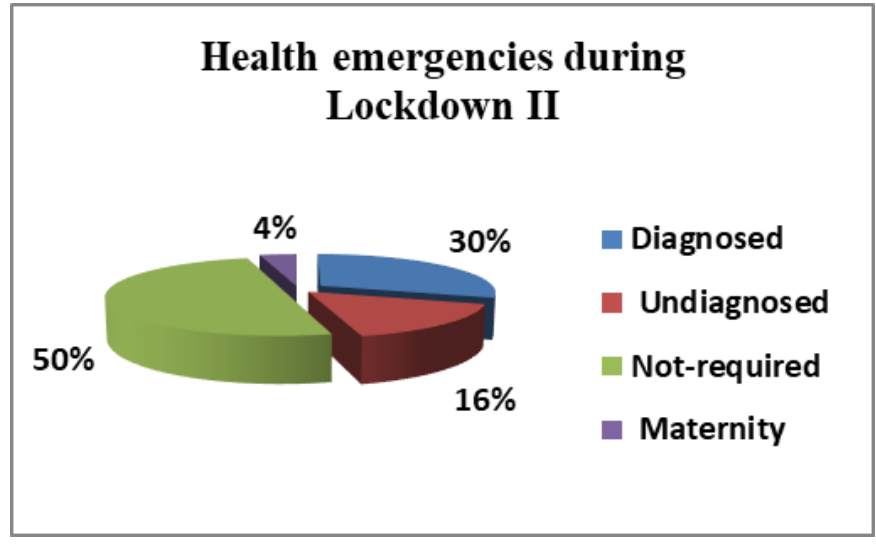

Source- Survey done by Researchers (Authors' own)

Then about the medication during lockdown I, among the diagnosed domestic workers (70\% according to figure 3) $26 \%$ and $8 \%$ maternity cases (cumulative $34 \%$ ) were treated in government hospital, while $16 \%$ were treated by private hospital ( $14 \%$ diagnosed workers and $2 \%$ maternity cases) but in emergency they stated, $12 \%$ took help of others (NGO, Health Workers, Welfare Clubs) whereas $8 \%$ did not seek further treatment. (Figure-5)

FIGURE 5

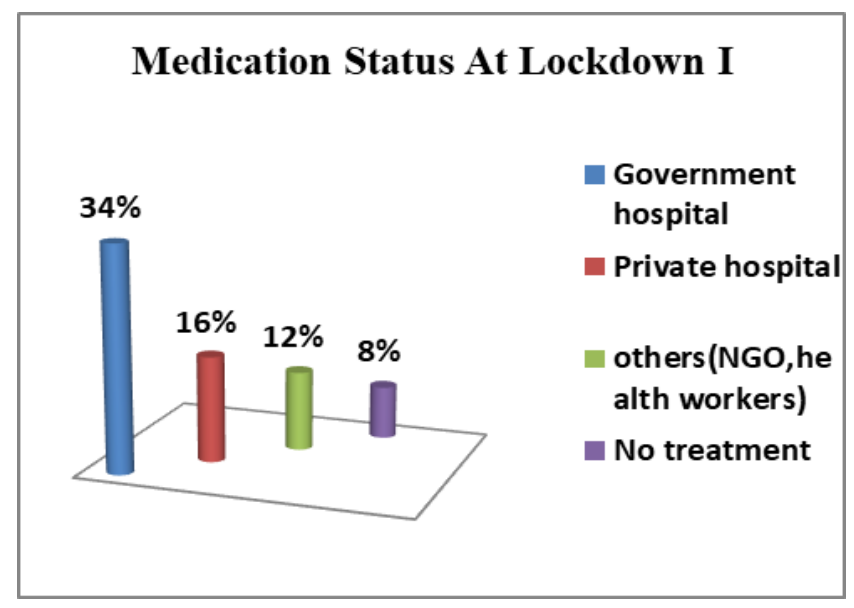

FIGURE 6

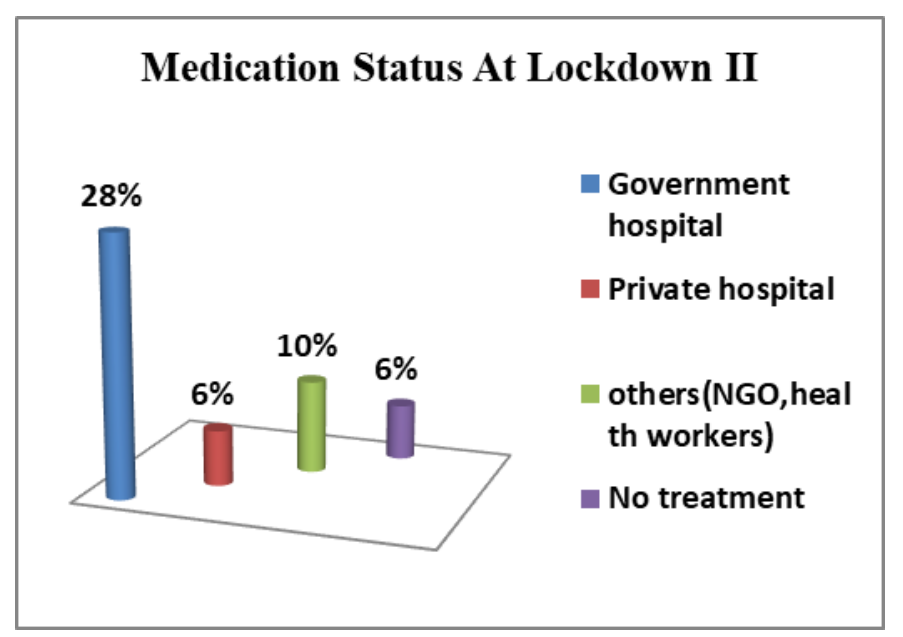

Source- Survey done by Researchers (Authors' own 
Respectively medication during lockdown II among the $50 \%$ those were diagnosed (figure 3), $28 \%$ domestic workers (26\% diagnostic workers and $2 \%$ maternity) took treatment from government hospital while $6 \%$ treated by private hospital (rest $4 \%$ diagnosed domestic workers and $2 \%$ maternity). It was found that $10 \%$ undiagnosed helped by others (NGO, health workers, Welfare Clubs etc.) while $6 \%$ amongst them did not seek any treatment. (Figure-6) This shows that whenever ill, these workers mostly go to government hospitals or charity hospitals or NGOs for their treatment as they have no savings or surpluses to be treated in private hospitals.

Regarding COVID exposure of domestic workers It was found that $60 \%$ of them remain unaffected (Figure 7 ) only $14 \%$ domestic workers (male-10\%, female-04\%) infected while $22 \%$ faced minor symptoms (male14\%, female $8 \%$ ). Some families of domestic workers also faced some symptoms around $4 \%$.

\section{FIGURE:7 COVID EXPOSURE OF DOMESTIC WORKERS AND THEIR FAMILIES}

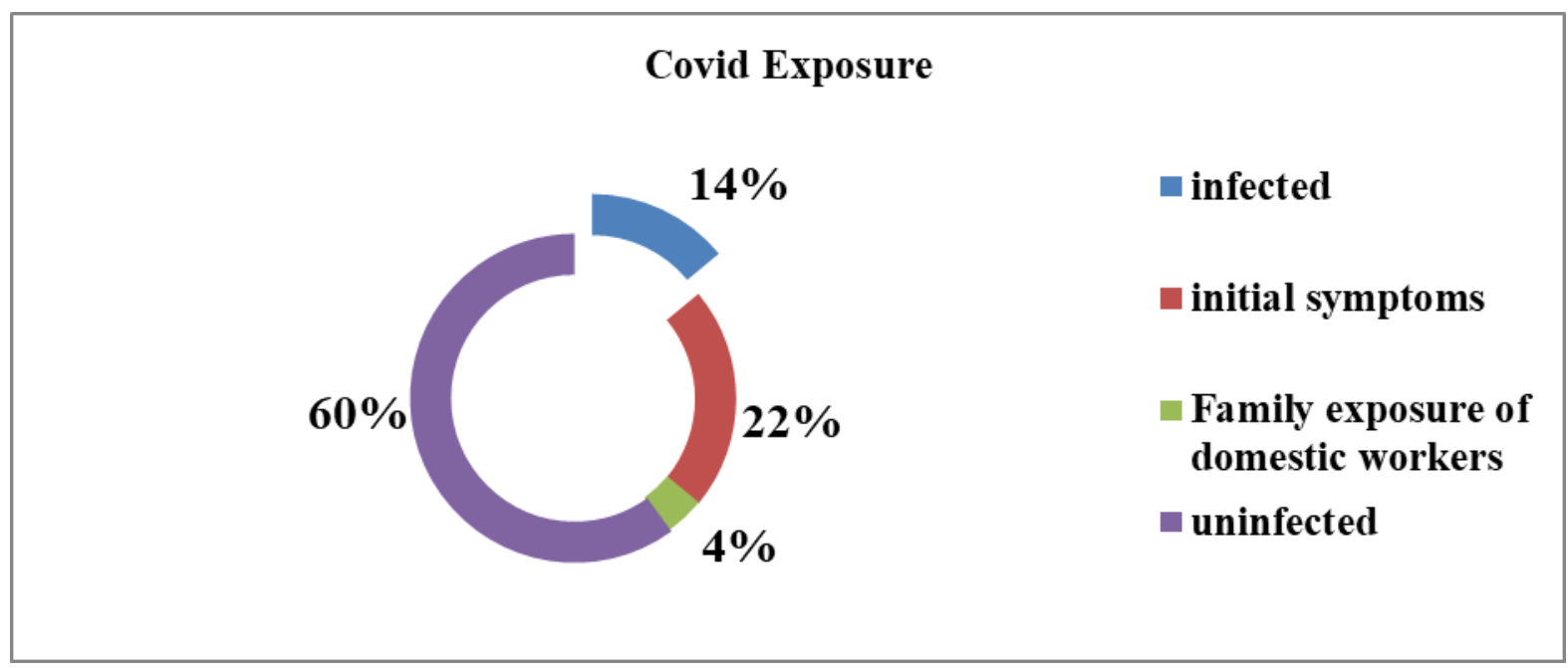

Source- Survey done by Researchers (Authors' own)

FIGURE 8

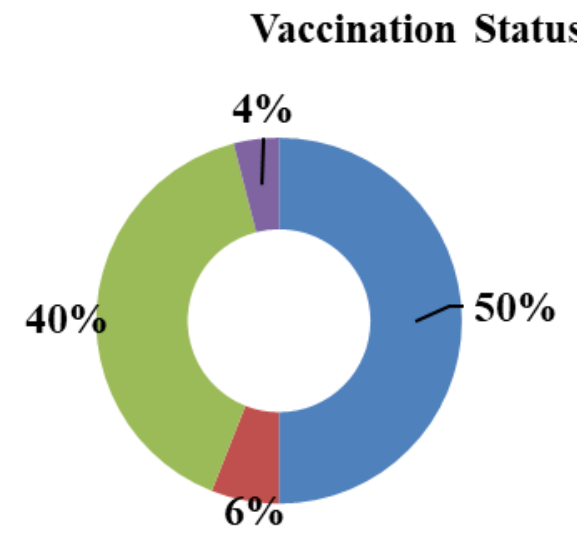

- Government Center

- Private Center

- Vaccination Camps

Not vaccinated

Source- Survey done by Researchers (Authors' own)

When asked about Covid vaccination survey found as domestic workers do not have enough cash for paid vaccine most likely $50 \%$ of workers got vaccination through government centres at free of cost, $40 \%$ likewise vaccinated through camps organized by others (community centres, NGOs etc.) also free, only $6 \%$ got vaccine from Private health centres which was paid dose and $4 \%$ not vaccinated yet. (Figure 8) Among the vaccinated workers $40 \%$ got vaccine during first phase of lockdown, $48 \%$ vaccinated during second phase and $8 \%$ got vaccine after unlock II. Rate of vaccination dose I and II monitored as $80 \%$ of workers have taken their II dose of vaccine and $16 \%$ workers have taken their dose I of vaccine. 
As government took initiative and practiced certain schemes to help vulnerable section of our society. These benefits acquired by domestic workers made their survival quite easier during and after pandemic. As result shows $60 \%$ domestic workers benefited with these schemes such- free rationing, vaccination, sanitization, masks distribution, cash (Rs.500) transferred to the female Jan-Dhan account holders etc. whereas $14 \%$ accounted not benefited due to not having ration card/Aadhar card or bank account and $26 \%$ did not specified and disclosed either they partially benefited or not (figure-9).
As requested by government to all the employers to help their employees during pandemic but survey found that only $24 \%$ domestic workers were helped by their employer such as food, cloth sanitizer, vaccination, monetary help etc. $50 \%$ of them denied for help from their employers and managed themselves, $10 \%$ helped from other sources (neighbors, relatives, friends etc.) and $16 \%$ found helped by NGO, welfare clubs/ organizations etc. (figure 10)

FIGURE: 9 STATUS OF GOVERNMENT BENEFITS ACCESSED BY DOMESTIC WORKERS

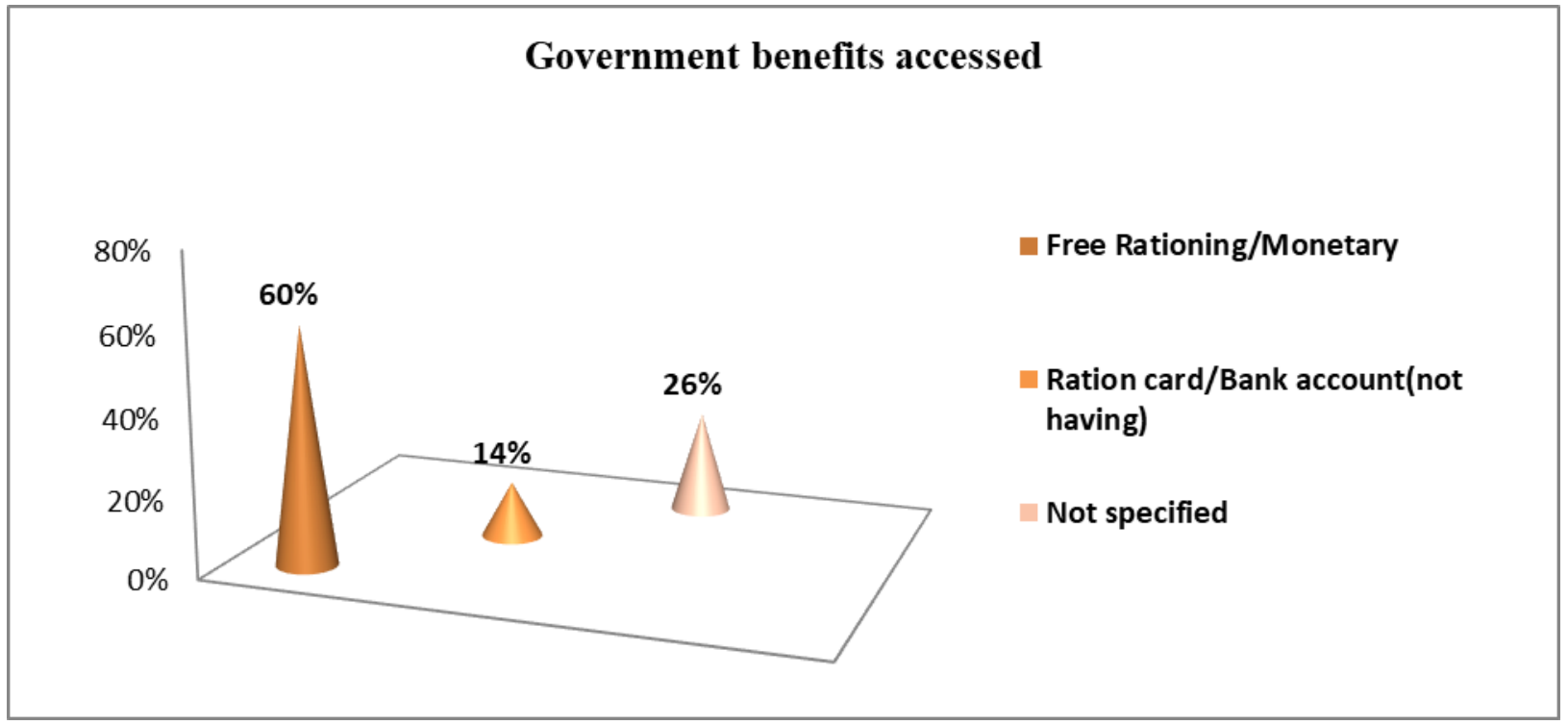

Source- Survey done by Researchers (Authors' own)

FIGURE 10: DOMESTIC WORKERS HELPED BY EMPLOYERS/OTHERS

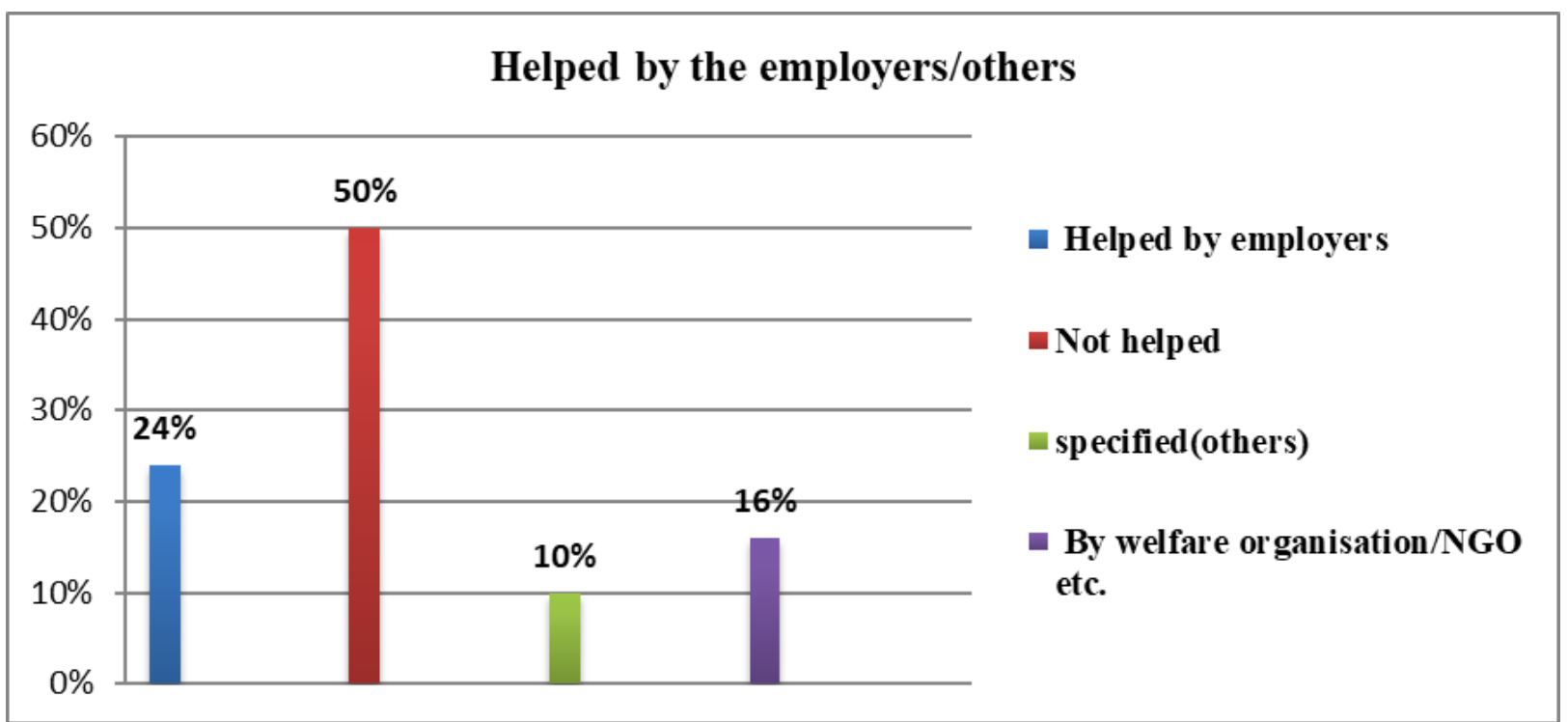

Source- Survey done by Researchers (Authors' own) 


\section{SUGGESTIONS AND RECOMMENDATIONS}

It is evident from the study that female workers participation is much higher than male domestic workers in domestic services. As they find it most suitable with their age, skills and maintaining work life balance. It was found in the study that exposure to Covid was not much in domestic workers (as $60 \%$ of them were not infected at all and $22 \%$ just initial symptoms figure -7) and male workers were infected more than female as they go outside more than females. Also, about vaccination maximum (90\%) took vaccine from government centres or camps but at the medication side it has been found that whenever ill these workers visit government hospitals or charitable one and only in case of emergency, they visit the private hospital. At the time of crisis weaker sections of society seek help and need support included domestic workers. Survey results found that some of the workers were helped by their employers as they were in need but surprisingly ratio was very less about one fourth of total (24\% figure-10). And a large section $50 \%$ was denied for help by the side of employer. Reasons may very as per situation and they managed at their own. But the help of NGOs and humane people of society was more pronounced and worked as a cushion for these workers in the time of crisis. Though maximum (60\%) were benefitted by government schemes such as free rationing, cash transfer, free vaccination, sanitization etc., but a certain section of workers denied benefits due to absence of certain formal documents such- Aadhar card, ration card, bank account etc. and results stated $26 \%$ did not revealed information either they were helped by these schemes / partially or not benefited.

On the basis of the findings of this field study it is suggested that

1. As domestic workers do not have savings or very less savings for crisis time so they should be provided help by the government, some relaxation should be given in case of formal documentation (if any worker is not having these formal documents) to provide relief to these workers and in this regard, powers can be given to DM/SDM or Gram Pradhan to help these workers (conditionally) at the time of crisis.

2. After the crisis whosoever is being helped without formal documentation, their formal documentation should be completed in every manner, so that in future they may not face this kind of problem and will be benefitted equally by government schemes
3. Moreover, these domestic workers should be brought under 'Digital Health Card' (started by government on 23 September 2021) and Ayushmaan Bharat Scheme to get medication help at the time of health problems and emergencies.

4. As it was found in the study that maximum domestic workers are female and their education as well as skill level is very poor so a special drive should be started to educate and train these workers so that they may upgrade their skills and after a certain age (when they are not able to do this work of moping and washing utensils) like male workers female workers may also switch over to some other trade or profession (like hygienic cooking, child rearing, massaging etc.) for their livelihood.

\section{CONCLUSION}

As pandemic remarked long lasting effect and gave an unbalanced ambience. Hence both caution and precaution became mandatory to be safe and protected. As pandemic is not over yet now and mankind is facing new challenges day by day so government should take action first to make formal documentation of all these workers. Secondly, should make their Digital Health Card on priority basis so that they can get medication and hospitalization facilities at the time of crisis and survive. No doubt, in India domestic workers are part of support system to middle class and upper-class society. Hence accountability must be shared to employers, workers and government as well. Then only risk can be assessed and minimized on time. It requires positive approach and immediate course of action at workplace and outside too. Apart from this government practices such as communication campaigns, guidelines and policies must be initiated to help these workers as has been recently done in MGNREGA Scheme in UP to provide these workers maternity and other benefits. No doubt, if above suggestions are taken into account, there can be much improvements in the lives of domestic workers.

\section{References}

[1] Ajay, khillare, P. Y. Sonawane and D. Madhulika, "the impact of work- life of women domestic workers on their family- life," IOSR Journal of business and management page-47-50, Vols. vol-18, no. issue-8, pp. 47-50, august 2016. 
[2] Jugal, Dr, Tomar and D. A. kishore:, "Demographic And Socioeconomic Profile of Female Domestic Workers In An Urban Slum of Central Delhi-A Mixed Method Study," Indian Journal of Applied Research, vol. vol. 8, no. issue6, pp. 1-2, june 2018.

[3] Sarkar, Kingshuk, Ghatak and Amrita, "Perils of lockdown and informal sector workers: Reflections in the time of Covid-19," 4-April-2020.

[4] Policy, Studies and I. For, "Black Immigrant Domestic Workers in the time of Covid-19," Notes from the Storm, New York, 2020.

[5] Rashee, Bhan, Dr.Gautam, Chowdhury, A. Rai and Mehra, "State of occupational safety and health practices at workplace for domestic workers in COVID19 and possibility for action," publications of the International Labor Office, Geneva, july 2021.

[6] N. Neetha, "Crisis After Crisis: The Pandemic and women's work," The Indian Economic Journal, pp. P-116, (2021).

[7] "A circular economy can promote decent work," ILO, 2021. 